\title{
Nursing activities in the prevention of american tegumentary leishmaniosis in the vicência/pe municipality
}

\begin{abstract}
Introduction: American tegumentary leishmaniasis (ACL) is defined as a zoonosis, of dermatological, non-contagious infections caused by the protozoan of the genus Leishmania, where its transmission is vector covering skin and mucosa; affecting other animals, to which man may be involved secondarily. It often occurs more in males than in adults, although there has recently been a greater involvement of children of both sexes.
\end{abstract}

Objective: To identify how nurses have been involved in the prevention of American cutaneous leishmaniasis in the municipality of Vicência / PE.

Method: This is a quantitative research of an exploratory nature for the analysis of nursing performance in the prevention of American cutaneous leishmaniasis in the municipality of Vicência / PE. The universe of this research was composed of 64 people from the city of Vicência / PE, infected and exposed to the protozoan of the genus leishmaniasis, in the last 10 years, being the municipality chosen by the infection rates for American tegumentary leishmaniasis, according to the Municipal Health Department of Vicência / PE.

Results: The present study evidenced that $68.8 \%$ to $87.5 \%$ do not conduct orientation campaigns; $87.5 \%$ do not perform Nursing consultations; and $92.1 \%$ do not perform a home view.

Conclusion: The study was able to identify how nursing practice has developed in the prevention of American cutaneous leishmaniasis in the municipality of Vicência / PE, based on lectures, campaigns, nursing visits, home visits, leaflet distribution, school and health, which makes one think that the same is lacking in most of these actions, due to the lack of management strategies, organization, planning, control and stimulation of activities in the attempt to achieve goals.

Keywords: cutaneous leishmaniasis, nursing, epidemiological monitoring, campaigns, nursing visits, home visits, leaflet distribution, school and health, diseases, phlebotominae, epidemiological, cutaneous leishmaniasis
Volume 2 Issue 5 - 2018

Eliana Lessa Cordeiro,' Tânia Maria da Silva, ${ }^{2}$ Liniker Scolfild Rodrigues da Silva, ${ }^{3}$ Emanuela Camila Vasconcelos, ${ }^{4}$ Karla Laís Lyra Carneiro Cazumbá, ${ }^{5}$ Camila Mendes da Silva ${ }^{6}$ 'Department of Neuropsychiatry and Behavioral Science, Salgado de Oliveira University, Brazil ${ }^{2}$ Department of Education, Academic Level, Salgado de Oliveira University, Brazi

${ }^{3}$ Obstetrician, University of Pernambuco, Brazil

${ }^{4}$ Salgado de Oliveira University, Brazil

${ }^{5}$ Salgado de Oliveira University, Brazil

${ }^{6}$ Nurse, University of Pernambuco, Brazil

Correspondence: Liniker Scolfild Rodrigues da Silva, Obstetric, Resident, Multiprofessional Residency Program in Collective Helath, Recife (PE), University of Pernambuco (UPE) and Medical Sciences College (FCM), Brazil, Tel +558199761 I231, Email liniker_14@hotmail.com

Received: July 08, 2018 | Published: September 06, 2018

\section{Introduction}

American Cutaneous Leishmaniasis (ACL) occurs in the Americas, from the southern United States to northern Argentina, and the incidence of this disease is increasing in Latin America, especially in Brazil. ${ }^{1}$ According to the Health Ministry (2010), it can be defined as an infectious, non-contagious disease caused by the protozoan of the genus leishmania of vector transmission affecting the skin and mucosa of the individual. Thus, it is primarily a zoonotic infection, which affects other animals, other than man, which can be involved secondarily. The cycle of infection is defined by lesions exclusively on the skin, beginning at the point of inoculation of infective promostigotas through the bite of the vector, any of the species leishmania causingthe disease. The primary lesion is usually unique, although occasional multiple stings of phlebotominae or local dissemination may generate a large number of lesions, which arise after a variable incubation period (from 10 days to three months), such as a progressing erythematous papule slowly to nodule, which with evolution, the notable polymorphism in lesions is highlighted. ${ }^{2}$ In relation to infection caused by American tegumentary leishmaniasis, the skin tissue and mucous membranes are most commonly affected, the most common manifestations of leishmaniasis ulcer: skin ulcer or in small numbers, with raised edges on frame and with no pain local. ${ }^{3}$ That other morphological aspects can be identified, such as: $[\ldots]$ infiltrated plaque, tuber, nodules and verrucous vegetative lesion, when the mucosa is damaged, may present erythematous-infiltrated, granular ulcerated appearance. In order of frequency, mucosal lesions are manifested mainly in the nose, hard palate, pharynx and larynx. ${ }^{3}$

From the epidemiological point of view, between 1999 and 2008, 269,122 cases of LTA were recorded, with an annual average of 26,912 cases in the State of Pernambuco. Thus, in the state, the disease occurs predominantly in male adults, although recently, it is perceived a greater commitment of children of both sexes. ${ }^{4}$ In this sense, in the city of Vicência / PE, from 2010 to 2013, 84 new cases of this pathology were notified. Regarding LTA control, it should be carried out comprehensively under the epidemiological surveillance aspects, through measures that aim to interfere in the transmission chain, as well as educational and administrative measures. In this way, epidemiological surveillance should cover from the detection of the 
case, its confirmation, registration of its therapeutics, registration of the basic variables, flow of care and information, until finalizing data analyzes distributed in epidemiological indicators and operational indicators, visualizing and characterizing the distribution of the disease and its clinical and epidemiological profile. ${ }^{5}$ In this context, with the implementation of the national epidemiological surveillance system, American tegumentary leishmaniasis became a compulsory notification disease, and the American Tegumentary Leishmaniasis Surveillance Program (PV-LTA) was created and treat early cases of American cutaneous leishmaniasis. ${ }^{6}$ This question becomes evident the new cases that arise, since the early diagnosis avoids sequels to the patient, since the therapy may be more effective.

Thus, drugs such as pentavalent antimonials are old, but used in the treatment of the disease to the present day, despite having significant adverse effects. ${ }^{7}$ Therefore, in view of the above, nursing as a profession that is also an educator has an important role in disseminating information and combating LTA, and may use different prevention strategies, such as: home visit, and the ability to communicate and relationship. ${ }^{8}$ In addition, it is important to highlight the importance of this study. Within this context, the proposed problem is: what are the nursing actions carried out in the municipality of Vicência/PE to carry out the prevention of American cutaneous leishmaniasis? And, it becomes important, since the theme is considered a health problem that is spreading in the city of Vicência / PE, in order to happen the reduction of the foci of contagion of the pathology, aiming to reduce the indices of the same in the municipality, this being the guiding axis of this research. Finally, it is also noticed that with the sugarcane monoculture, in the municipality of Vicência / PE (which has a sugar mill), besides the permanent culture of the banana, can provide an increase in the population of the sand fly mosquito, vector the results of this research serve as a theoretical contribution to the health professionals working in the Basic Health Units and in the Family Health Programs on the relevance of the discussion about the role of the nurse in the prevention of American cutaneous leishmaniasis. The main objectives of this research were: to identify how the nurse's role in the prevention of American tegumentary leishmaniasis in the municipality of Vicência / PE has been occurring; to verify the infection rates of American tegumentary leishmaniasis in the last three years; compare the indices found with the indices of the last 10 years, the in order to observe the increase or incidence of American tegumentary leishmaniasis in the municipality of Vicência / PE; to know the projects developed by the municipality of Vicência-PE, in the prevention and combat of the emergence of new cases of American tegumentary leishmaniasis; to analyze the adoption by the nursing area of preventive measures of American tegumentary leishmaniasis municipality of Vicência / PE; investigating how the population affected by the pathology has been perceiving the health actions developed for the prevention and treatment of LTA .

\section{Methodology}

It is a predominantly quantitative study which has the natural environment as a direct source of data, and the researcher as a fundamental instrument, ${ }^{9}$ within a deductive approach to data analysis and giving greater importance to the meanings attributed by people to things and to life. ${ }^{10}$ In this way, it is a study that was carried out in an area where there is little structured knowledge about this subject, which can provide the exploration of the reality, studied, in search of a greater knowledge in order to better describe the phenomenon studied. ${ }^{11}$ The universe of this research was composed of 64 people from the city of Vicência / PE, infected and exposed to the protozoan of the genus leishmaniasis, in the last 10 years, being the municipality chosen by the infection rates for American tegumentary leishmaniasis, according to the Municipal Health Department of Vicência/PE. A structured questionnaire was used, containing closed questions that were answered, in order to clarify the researched problem. The inclusion criteria used were: people who carry the disease or know someone with this pathology; who are over 18 years of age; resides in the municipality of Vicência / PE; voluntarily participate in the research, signing the Free and Informed Consent Form (TCLE). The exclusion criteria were: people who do not carry the disease or do not know someone with this pathology; who are not over 18 years of age; who does not reside in the municipality of Vicência / PE; do not voluntarily participate in the research, not signing the TCLE. With questionnaire application, the risks were usually minimal (or possible constraints for exposing particular points of view, without physical risks). This research is of great importance to evaluate the nursing and authorities' actions, as well as the knowledge of the population about the risks of infection by the American tegumentary leishmaniasis protozoan in the municipality of Vicência / PE, creating strategies for prevention and health promotion. The data were collected individually, from the application of questionnaire and EHIC, after approval of the Ethics and Research Committee (CEP) 819.450, under the number of CAEE: 33894814.3.0000.5289 and after answering the questionnaires were sealed in envelopes individual and delivered to the statistician to perform statistical analysis, using the softwares Statistical Package for the Social Sciences (SPSS) and Microsoft Excel, in order to deform graphs $\backslash$ tables for presentation the variables and data analyzed.

\section{Results}

Table 1 presents the social profile of carriers and noncarriers of American cutaneous leishmaniasis in the municipality of VicenzaPE, between October and November 2014. Regarding the variables, it was found that $84.38 \%$ of the interviewees were female; $39.1 \%$ are between 18 and 28 years of age, $34.3 \%$ between 40 and 59 years of age, and most of them reside in João Ramos Maranhão Lot 31.2\% and Enbuho Imbu 26.5\%. Table 2 shows the performance of nursing in the prevention of cutaneous leishmaniasis in the Family Health Units in Vicenza-PE municipality, between October and November 2014. According to the results, it can be seen that $68.8 \%$ do not conduct lecture-type educational activities; $67.1 \%$ do not conduct health education campaigns for the prevention or identification of risk factors; $87.5 \%$ do not perform nursing consultations related to the focus of prevention of American cutaneous leishmaniasis and 92\% do not carry out the intervention in the home visit. Table 3 deals with the knowledge of the population about projects developed by Vicência / PE municipality between October and November 2014. Analyzing the results of Table 4, it can be seen that nursing does not adopt preventive measures to combat leishmaniasis infection, where it can be seen that the guidelines at the primary health care $(73.5 \%)$, leaflet distribution (93.8\%) and guidance in schools $(89.0 \%)$ are not carried out. Figure 1 shows the American cutaneous leishmaniasis infection indices in the municipality of Vicenza-PE in the period from January 2004 to November 2014. In view of the results it is noticed that the number of men infected $61.5 \%$ exceeds women $38.5 \%$. Figure 2 shows the infection rates of cutaneous leishmaniasis in the municipality of Vicenza-PE in the period from January 2012 to November 2014. According to the results, male respondents accounted for the highest percentage of cases recorded in the evaluation period of the present study, $68.1 \%$, where women presented $3.9 \%$. 
Table I Social profile of the carriers and non-carriers of American cutaneous leishmaniasis in the municipality of Vicência-PE, Oct and Nov / 2014

\begin{tabular}{lll}
\hline Variables & n. 64 & $\%$ \\
\hline Gender & 10 & 15,7 \\
Male & 54 & $84,3^{*}$ \\
Female & & \\
Age & 25 & $39,1 *$ \\
I8-28 years & 09 & 14,1 \\
$29-39$ years & 22 & 34,3 \\
$40-59$ years & 07 & 11,0 \\
$60-79$ years & 01 & 1,5 \\
$80-89$ years & & \\
Place of Residence & 14 & 22,0 \\
Comunidade Mãe Rainha & 17 & 26,5 \\
Engenho Imbu & 09 & 14,1 \\
Engenho Usina Barra & 20 & $31,2 *$ \\
Loteamento João Ramos Maranhão & 6,2 \\
Comunidade Quilombola Trigueiros & & \\
\hline
\end{tabular}

Table 2 Nursing performance in the prevention of American tegumentary leishmaniasis in the Family Health Units in the Municipality of Vicência-PE, Oct and Nov / 2014

\begin{tabular}{lll}
\hline Variables & n. 64 & $\%$ \\
\hline Lecture & 20 & 31,2 \\
Peform & 44 & $68,8^{*}$ \\
Do not peform & & \\
Campaings & 21 & 32,9 \\
Peform & 43 & $67, I^{*}$ \\
Do not peform & & \\
Nursing consultation & & 12,5 \\
Peform & 08 & $87,5^{*}$ \\
Do not peform & 56 & \\
Home visit & & 7,9 \\
Peform & 05 & $92,1^{*}$ \\
\hline Do not peform & 59 & \\
\hline
\end{tabular}

Table 3 Knowledge of the population about projects developed by the municipality in the fight against leishmaniasis in the city of Vicência-PE, Oct and Nov / 2014

\begin{tabular}{lll}
\hline Variables & n. 64 & $\%$ \\
\hline They know & 07 & 11,0 \\
Do not know & 57 & $89,0 *$ \\
\hline
\end{tabular}

Table 4 Indicates preventive measures adopted by nursing in the case of infection by American tegumentary leishmaniasis in the municipality of Vicência-PE, in the period of Oct and Nov / 2014

\begin{tabular}{lll}
\hline Variables & n. 64 & $\%$ \\
\hline Leaflet distribution & & \\
Peform & 04 & 6,2 \\
Do not peform & 60 & $93,8^{*}$ \\
Orientation in Schools & & \\
Peform & 07 & 11,0 \\
Do not peform & 57 & $89,0^{*}$ \\
Orientation in primary health care & & \\
Peform & 17 & 26,5 \\
Do not peform & 47 & $73,5^{*}$ \\
\hline
\end{tabular}

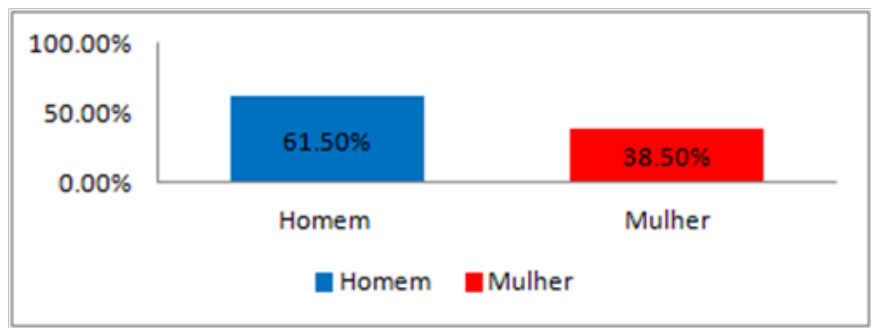

Figure I Infection rates of American tegumentary leishmaniasis in the municipality of Vicência-PE, Jan / 2004 to Nov / 20 I4.

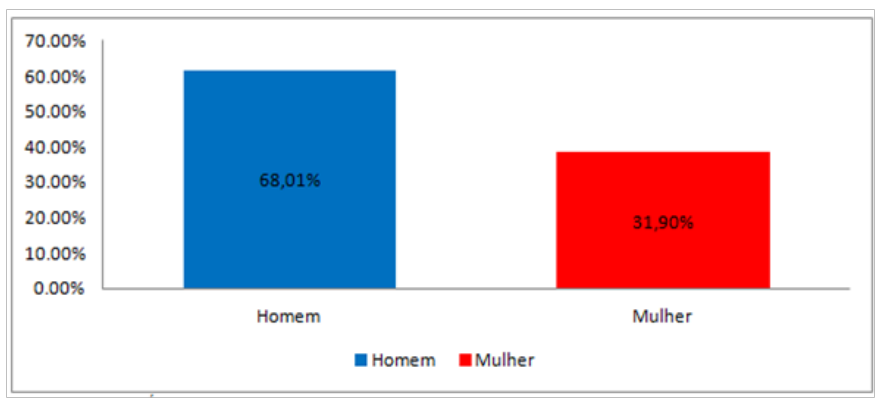

Figure 2 Infection rates of American tegumentary leishmaniasis in the municipality of Vicência-PE, Jan / 2012 to Nov / 2014.

\section{Discussion}

LTA occurs in both sexes and all age groups, meanwhile, in the country average, those older than 10 years predominate, representing $90 \%$ of the cases and the male sex, $74 \%$, is perceived that in the study $84.3 \%$ were of women interviewed, which makes it possible to perceive the female willingness to participate in research and to seek health services, as opposed to men. ${ }^{12}$ The age distribution of the population to which the sample belongs is $39.1 \%$ of the age between 18-28 years may be due, at least partially, to the fact that the interviewers who were used in the field work belong to the community itself, allowing some confidentiality in the treatment of information. ${ }^{13}$ Analyzing data from LT and Ross's work (1903), one can perceive a change in the epidemiological aspect of leishmaniasis. Previously, cutaneous leishmaniasis was basically considered a zoonosis of wild animals, being accidentally transmitted to humans as it entered the forests, for exploration, extraction of wood, opening of roads and mining, while today it is observed that area equivalence in the study 
for LT. LT presented a very similar distribution between the urban to rural areas, with approximately $50 \%$ of the cases related to the rural area and a similar percentage, for the cases, in the urban zone. The main factors responsible for the increasing number of cases in the urban area are: I) the migratory process; II) precariousness in basic sanitation; III) low socioeconomic status; IV) rampant deforestation for construction of settlements, roads and factories; V) growth of agriculture and livestock, among others, destroying and invading the habitat of sandfly vector Leishmaniasis. ${ }^{5}$

The detection of cases of American Cutaneous Leishmaniasis can occur through active search of cases in the area of focus, actions of health agents, spontaneous demand to health units and referral of suspects. The control actions of American tegumentary leishmaniasis should be the subject of a continuous programming that has as objective the diagnosis of the patient, through the attendance of demand and active search of cases, with supply of inputs for complementary diagnosis, investigation of foci and adequate registry of its occurrence, which can be done by the nurse, from the home visits performed at the FHT, with the complementary diagnostic services requested by the responsible physician. ${ }^{14}$ In order to avoid the risks of transmission, some preventive measures of individual or collective environments should be stimulated, such as: ${ }^{6}$

Use of repellents when exposed to environments where vectors can usually be found;

I. Avoid exposure at times of vector activity (twilight and night);

II. Use of fine-mesh bed nets, as well as the siting of doors and windows;

III. Environmental management through the cleaning of yards and lands, in order to alter the conditions of the environment that allow the establishment of breeding sites for immature forms of the vector;

IV. Pruning of trees in order to increase sunshine in order to reduce soil shading and avoid favorable conditions (temperature and humidity) for the development of phlebotominal larvae;

V. Adequate fate of organic waste in order to prevent the approach of commensal mammals, such as marsupials and rodents, likely sources of infection for phlebotomines;

VI. Periodical cleaning of pet shelters;

VII. Maintenance of domestic animals distant from the home at night, in order to reduce the attraction of sand flies to this environment;

VIII. In potential transmission areas, a safety range of 400 to 500 meters between the residences and the forest is suggested.

However, a strip of this nature will have to be planned to avoid erosion and other environmental problems. All these measures can be instituted and monitored by the primary health care nurse, not only during home visits, but also in lectures in partnership with related organs, carried out in communities susceptible to the disease and with the presence of pathology already confirmed. ${ }^{6}$ According to protocols or other technical regulations established by the Federal Nursing Council (COFEN), approves Resolution no. 195 of February 18,1997 , observing the legal provisions of the profession, conducting nursing consultations, requesting complementary examinations and prescribing medications; plan, manage, coordinate and evaluate the actions developed by the ACS; supervise, coordinate and carry out ongoing education activities of the ACS and the nursing team; contribute to and participate in the activities of Permanent Education of the Nursing Assistant, ACD and THD; and to participate in the management of the necessary inputs for the proper functioning of the primary health care, to plan, manage, coordinate, execute and evaluate the USF. ${ }^{14}$

The information on the prevention of diseases is an essential tool to develop health promotion projects. Due to the position geographical area of Brazil and its extensive territorial area, there are several infectious diseases and different according to the Brazilian regions. Some of them, however, are widely distributed in the territory and even with their expansion the populations are unaware of basic information such as prevention, symptoms and treatment. Vigilance management presents a challenge for local health systems, since it is not fully structured in municipalities and its managers do not always have the knowledge, physical and human material needed to develop actions adequately. ${ }^{14}$ Generally the population affected by LTA, or that is in endemic area, has little information of what the disease is, with this, these authors carried out an educational activity with students and teachers of several schools of a municipality where they used posters, booklets and lectures, aiming at raising awareness and awareness of the group that had knowledge about the disease and could become informants of the disease in their homes and communities, helping to control the endemic and consequently improving the quality of life. ${ }^{15}$ The attributions of the professionals belonging to the Team were also established by Ordinance No. 648, of March 28, 2006 of the Ministry of Health, and can be complemented by local management, among them: (health promotion and protection, disease prevention, diagnosis, treatment, rehabilitation and health maintenance) to individuals and families at USF and, when appropriate or necessary, at home and / or in other community spaces (schools, associations etc.), in all phases of human development: childhood, adolescence, adulthood and the elderly; during the time and frequency required according to the needs of each patient. ${ }^{16}$ As guidelines on health defined the following procedures as the main nursing care for the LTA patient: ${ }^{16}$

I. Inform the client about the importance of early treatment;

II. Orient the client in relation to the transmission mechanism of the disease;

\section{Verify the likely type of transmission (wild or urban);}

Orient the client regarding the route of administration of the medication, according to medical prescription, and for the average duration of thirty days of treatment; Carry out cleaning of the lesions with $0.9 \%$ saline solution in jets, protecting them with non-adherent dressings; Attempt for complaints of upper airway obstruction, elimination of nasal crusts and epistaxis, as they may indicate hematogenous metastasis to the mucosa of the nasopharynx; Direct the client not to make use of alcoholic beverages during the treatment. The cause of higher incidence in this sex is related to the same concept of occurrence in adults, which is the greatest exposure to infected sandfly..$^{12}$ The higher frequency of LT in men is also related to the fact that these are more present in extradomiciliary places, performing work activities, mainly in the vector habitat, while women are, in general, less exposed to agricultural regions and, in most cases, occupying intra and peri-residential environments. ${ }^{17}$

Therefore, the study was able to identify how nursing practice has developed in the prevention of American cutaneous leishmaniasis in the municipality of Vicência / PE, based on lectures, campaigns, nursing visits, home visits, leaflets, school and post orientation health, what 
makes you think that it is d eixando to be desired in most of these actions, due to lack of management strategies, organization, planning, control and activity stimulation in an attempt to achieve goals. It is worth noting that, in terms of infection rates for American tegumentary leishmaniasis in the last 3 years, the study was able to show the male population with an index well above the desired average, which makes rethinking of more effective prevention strategies such as guidance on the use of repellents, long-sleeved shirts, long trousers, socks and shoes, avoiding exposure during vector activity times ( twilight and night), do not take pets to the working environment, no area Lizar burning and deforestation, pruning trees, in order to increase heat stroke in order to reduce soil shading and avoid favorable conditions for the development of larvae phlebotomines, periodic cleaning of pet shelters. However, when comparing these rates with ín dices the past 10 years $\mathrm{h}$ ear $\mathrm{pl}$ and a decrease in considerable cases, despite the failure of nursing in the prevention and investigation, the Department of $\mathrm{H}$ ealth with the Agency Fi Cruz made use strategies of insecticides in the places of focus, in order to reduce the proliferation of the mosquito.

Given the results, the study could not point to the adoption of preventive measures by nursing and were not implanted tados any fighter project LTA decided by current health policy, which is to rever practices mainly nurses knowledge which has the ability to expose its knowledge about the problem and to develop, together with the Municipal Health Department, an effective project aimed at prevention. Thus, from these findings are suggested as actions to be developed by nurses based on Surveillance Manual and pidemiológica: identify health facilities and prof is sional who will attend the infected patients, capacitor professionals who will make the multi uipe eq in diagnosis and treatment, sensitize professional network for suspected CLI single, establish routines of care to patients, training of teams of Programs of the communitarians people of Health, investigate all patients who evolved to death and indicate euthanasia only when diseased animals become aggravated for infections that may lead the animal to suffering. However, by performing such actions, the professional practice of nursing prevention becomes effective and complete.

\section{Acknoledgements}

None.

\section{Conflict of interest}

The author declares threr is no confict of interest.

\section{References}

1. Monteiro WM, Neitzke HC, Silveira TGV, et al. Poles for the production of American Tegumentary Leishmaniasis in the northern part of the State of Paraná, Brazil. Caderno de Saúde Pública. 2009;25(5):1083-1092.

2. Arruda MM. Leismanioses. PhD in Veterinary Medicine and Animal Experimentation. Specialist Technical Consultant of the Ministry of
Health. Secretariat of Health Surveillance. General Coordination of Public Health Laboratories. Brasília; DF, 2008.

3. Neto FXP NETO, Rodrigues AC, Silva LL, et al. Otorhinolaryngologic Manifestations Relating American Tegumentary Leishmaniasis: Literature Review .International Archives of Otorhinolaryngology. 2008;12(4):531537.

4. Penna GO, Domingues CMAS, Siqueira-Jr JB, et al. Dermatological diseases of compulsory notification in Brazil. Anais Brasileiros de Dermatologia. 2011;86(5):865-877.

5. Basano SA, Camargo LMA. American cutaneous leishmaniasis: history, epidemiology and control perspectives. Revista Brasileira de Epidemiologia. 2004;7(3):328-337.

6. Brazil, MS. Manual of Surveillance of American Cutaneous Leishmaniasis. 2.nd. Ministery of Health: Brasília-DF; 2008.

7. Ferreira CC, Marochio GG, Partata AK. Study on American Cutaneous Leishmaniasis with a Focus on Pharmacotherapy. Scientific Journal of ITPAC. 2012;5(7):1.

8. Bezerra CA. Technical manual for health promotion and prevention of risks and diseases in supplementary health. 3.rd. Ministery of Health: Rio de Janeiro; 2009.

9. Godoy AS. Qualitive researsh: fundamental types. Revista de Administração de Empresas. 1995;35(3):20-29.

10. Almeida MS. Project elaboration, CBT, dissertation and thesis: a simple, practical and objective approach. São Paulo: Atlas; 2011.

11. Gil AC. How to elaborate research projects. 5.th. edition. São Paulo:Atlas; 2010.

12. Missawa NA, Maciel GBML, Rodrigues H. Geographical distribution of Lutzomyia (Nyssomyia) Witmani in the State of Mato Grosso (Antunes \& Coutinho, 1999). Revista da Sociedade Brasileira de Medicina Tropical. 2008;41(4):369-373.

13. Batista FMA, Machado FFOA, Silva JMO. Lesshmanıse: epidemiological profile of cases notified in the state of piauí between 2007 and 2011 . Univap Magazine. 2014;20(35):44-55.

14. Brazil MS. American Cutaneous Leishmaniasis Control Manual. Organization: Technical Management of Diseases Transmitted by Vectors and Anthropozoonoses. Coordination of Epidemiological Surveillance. National Epidemiology Center. National Health Foundation. Ministry of Health: Brasília; 2000.

15. Uchôa CMA, Serra CMB, Magalhães CM. Health education: teaching on American cutaneous leishmaniasis. Cadernos de Saúde Pública. 2004;20(4):935-941.

16. Waldman EA. Glossary of epidemiology iology. Epidemiological Report of the SUS; 1992.

17. Guerra JAO, Barbosa MGV, Oureiro ACSP, et al. American tegumentary leishmaniasis in children: epidemiological aspects of cases treated in Manaus, Amazonas, Brazil. Cadernos de Saúde Pública. 2007;23(9):2215-2223.

\section{Annex}


Figure I Map of the city of Vicência / PE.

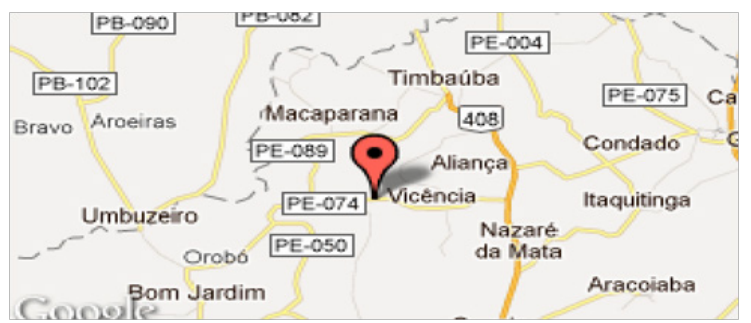

Source: Google Maps

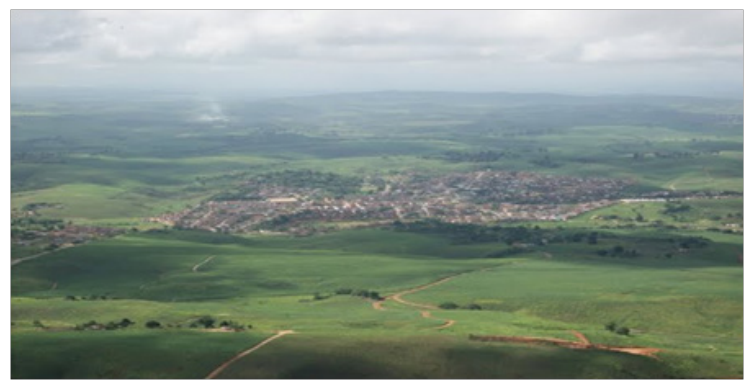

Figure 2 Aerial photo of the city of Vicência / PE.

Source: Google Maps

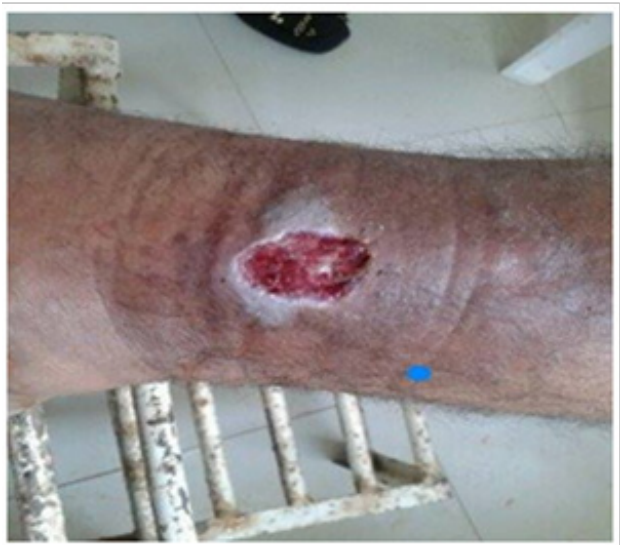

Figure 3 Skin lesions

Source: Prepared by the authors

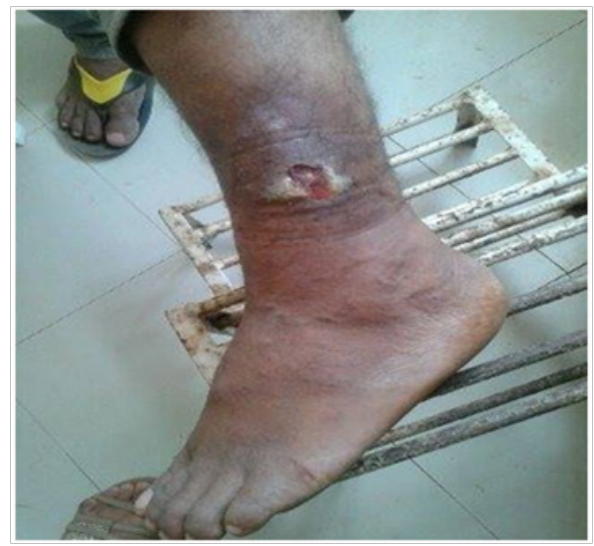

Figure 4 Skin lesions.

Source: Prepared by the authors

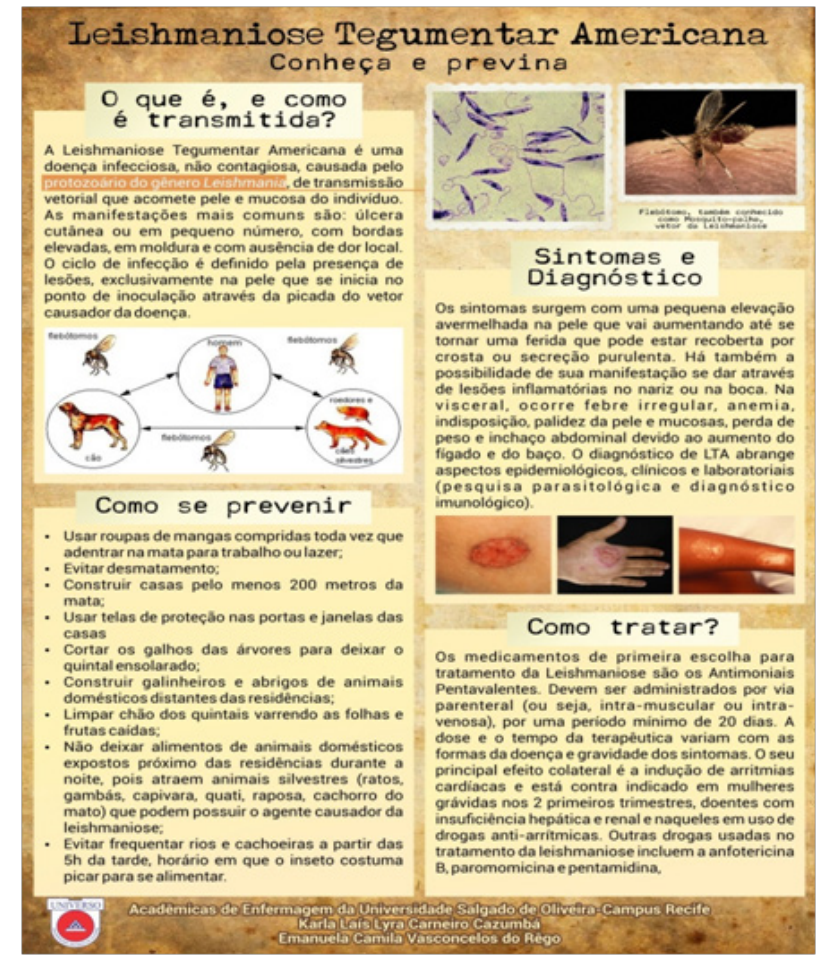

Figure 5 Informational booklet.

Source: Prepared by the authors. 